\title{
Kidney Disease in Diabetes Mellitus: Cross-Linking between Hyperglycemia, Redox Imbalance and Inflammation
}

\author{
Rayne Gomes Amorim, ${ }^{\circledR}$ Glaucevane da Silva Guedes, Sandra Mary Lima Vasconcelos, Juliana Célia de Farias Santos
}

Universidade Federal de Alagoas - Faculdade de Nutrição, Maceió, AL - Brazil

\begin{abstract}
Chronic hyperglycemia is the key point of macro- and microvascular complications associated with diabetes mellitus. Excess glucose is responsible for inducing redox imbalance and both systemic and intrarenal inflammation, playing a critical role in the pathogenesis of diabetic kidney disease, which is currently the leading cause of dialysis in the world. The pathogenesis of the disease is complex, multifactorial and not fully elucidated; many factors and mechanisms are involved in the development, progression and clinical outcomes of the disease. Despite the disparate mechanisms involved in renal damage related to diabetes mellitus, the metabolic mechanisms involving oxidative/inflammatory pathways are widely accepted. The is clear evidence that a chronic hyperglycemic state triggers oxidative stress and inflammation mediated by altered metabolic pathways in a self-perpetuating cycle, promoting progression of cell injury and of end-stage renal disease. The present study presents an update on metabolic pathways that involve redox imbalance and inflammation induced by chronic exposure to hyperglycemia in the pathogenesis of diabetic kidney disease.
\end{abstract}

\section{Introduction}

Diabetic kidney disease (DKD) is a devastating outcome of diabetes mellitus (DM), responsible for high morbidity and overall mortality. It is clinically characterized by persistent renal dysfunction for a period equal to or longer than three months, marked by urinary excretion of albumin $>30 \mathrm{mg} / 24 \mathrm{~h}$ or an albumin/creatinine ratio (ACR) $\geq 30 \mathrm{mg} / \mathrm{g}$ or glomerular filtration rate $(\mathrm{GFR})<60 \mathrm{~mL} / \mathrm{min} / 1.73 \mathrm{~m}$ after a hyperfiltration phase, in addition to structural abnormalities (e.g. diabetic glomerulosclerosis) in individuals with previous diagnosis of DM. ${ }^{1,2}$

It is estimated that approximately 425 million people have DM in the world, with a projected increase by $48 \%$ to the yar of 2045. Approximately 12.5 million people are diagnosed with DM in Brazil, which occupies the third

\section{Keywords}

Diabetes Mellitus/complications; Kidney, Diseases; OxidationReduction; Inflammation; Oxidative Stress; Renal Dialysis.

\footnotetext{
Mailing Address: Juliana Célia de Farias Santos •

Universidade Federal de Alagoas Ringgold standard institution - Faculdade de Nutrição - Avenida Lourival de Melo Mota, Km14, Postal Code 57072-970, Tabuleiro do Martins, Maceió, AL - Brazil

E-mail: jcfsnut@hotmail.com

Manuscript received August 29, 2018, revised manuscript December 19, 2018, accepted February 13, 2019
}

DOI: $10.5935 / a b c .20190077$ position in number of individuals with DM in the world in 2017. ${ }^{3}$ Nearly $90 \%$ of DM patients develop microvascular and macrovascular complications; DKD is considered one of the most severe clinical outcomes, affecting 20-40\% of the patients, most of them type 2 DM patients. ${ }^{1}$ DKD is currently the main cause of dialysis in developed countries, the second main cause in Brazil. ${ }^{4-6}$

DKD is a progressive and irreversible condition, whose pathogenesis has been associated with functional and structural changes of renal cells in response to metabolic stress induced by excessive glucose inflow, by means of activation of specific metabolic pathways linked to redox imbalance and inflammation. ${ }^{7}$

Although many classical mechanisms involved in the development and progression of DKD have been described, new molecular and epigenetic pathways have been suggested to be responsible for the early kidney functional loss and DKD-related complications. ${ }^{8}$

In this review we discuss current knowledge of metabolic pathways involving redox imbalance and inflammation induced by chronic exposure to hyperglycemia in the pathogenesis of DKD, aiming to propose new paradigms.

Pathophysiology of DKD induced by hyperglycemia: new paradigms

DKD is a chronic metabolic disease in which hyperglycemia causes dysfunction of renal and vascular cells. The pathophysiology of DKD and the consequent end-stage renal disease requiring dialysis is caused by a chronic hyperglycemic state that leads to activation and changes of metabolic pathways and hemodynamic dysfunction. Some of these changes occur in an integrated way, leading to several other changes. Although diabetic hyperglycemia is an important but not crucial factor for the development of glomerular lesions in DKD, we will describe metabolic changes induced by intermittent and chronic exposure to hyperglycemia. The following topics will be discussed: glucose auto-oxidation, polyol and hexamine pathways, formation of advanced glycation end-products (AGEs), synthesis of nicotinamide adenine dinucleotide phosphate (NADPH) oxidase (NOX), protein kinase $\mathrm{C}(\mathrm{PKC})$ activation, and abnormal activity of angiotensin II (Ang II). 9,10

\section{Glucose uptake by diabetic kidney cells}

Hyperglycemia is the main clinical manifestation of DM, the main driving force for the development of chronic complications of the disease, including DKD. It is caused by two main mechanisms: the first involves dysfunction and apoptosis of pancreatic beta cells caused by an autoimmune abnormality (type $1 \mathrm{DM}$ ), and the second results from an 
overstimulation of insulin synthesis and secretion in the presence of insulin resistance (IR), mostly associated with overweight/obesity, which characterizes type $2 \mathrm{DM}^{11}$

In the context of obesity, which is common in patients at risk of type 2 DM, IR results from increased levels of free fatty acids (FFAs), and the FFA by-products pro-inflammatory cytokines and diacylglycerols (DAG), that inhibit phosphorylation of the insulin receptor substrate 1 (IRS-1) in phosphorylation domains (serine/threonine), preventing the propagation of signals to the translocation of the glucose transporter-4 (GLUT4) translocation to the plasma membrane. This affects the interaction between insulin and its receptor, leading to decreased glucose uptake by insulin-dependent cells, and ultimately hyperglycemia and hyperinsulinemia. ${ }^{12,13}$

In additional, in obese diabetic individuals, excessive accumulation of fat causes stress of adipocytes by hyperplasia and hypertrophy, leading to hypoxia and subclinical inflammation, increased macrophage infiltration and release of pro-inflammatory cytokines - tumor necrosis factor alpha (TNF- $\alpha$ ), interleukin-6 (IL-6) and interleukin-1 (IL-1) - which, in turn, aggravates IR. ${ }^{12,14}$ TNF- $\alpha$ stimulates the secretion of other cytokines and chemokines and directly activates the transcription factor-kappa B (NF-kappa B), thereby leading to maintenance of chronic hyperglycemia, by affecting glucose uptake and promoting IR. ${ }^{15}$

In attempt to reestablish homeostasis, glucose uptake occurs in cells not dependent on GLUT4, and hence, non-insulin-dependent, such as renal cells, that have GLUT 1 and GLU2 as glucose transporters. These glucose carriers do not regulate glucose entry into cells, leading to glucotoxicity. In this situation, there is elevated expression of these transporters, leading to increased entry of glucose into renal cells, as occurs with the high-affinity glucose transporter GLUT 2, stimulated by hyperglycemia, and the sodium-glucose co-transporter (SGLT) 1 and SGLT 2, responsible for tubular reabsorption. ${ }^{16,17}$ Thus, in DM patients, glucose reabsorption in the proximal tubule is increased, contributing to hyperglycemia and, consequently, hyperfiltration. ${ }^{18}$

Generation of reactive oxygen and nitrogen species (RONS) induced by hyperglycemia

Glucotoxicity is caused by an inability of the cells to compensate for the increased glucose uptake in case of IR/hyperglycemia, as in DM. Increased stimulation of glucose oxidation pathways in non-insulin-dependent cells leads to the activation of alternative pathways, increased production of RONS and oxidative stress (OS) in hyperglycemic state. ${ }^{19}$

\section{Glucose auto-oxidation}

In glycemic homeostasis and in the absence of oxygen, glycolysis is the primary energy source in the cells. By-products of these reactions are coenzymes responsible for the uptake of high energy electrons, released during oxidation-reduction (redox) reactions, that participate in additional energy pathways. ${ }^{20}$ The synthesis of substrates by glycolysis activates two other energy pathways: the tricarboxylic acid cycle (or the Krebs cycle) and the electron transport chain (ETC) (or the oxidative phosphorylation) in the mitochondria through protein complexes. ${ }^{20-22}$
In DM, the hyperglycemic state promotes the overactivation of the three main energy pathways previously described. The increased stimulation of glycolysis and Krebs cycle result in elevated production of reduced flavin adenine dinucleotide $(\mathrm{FADH} 2)$ and reduced nicotinamide adenine dinucleotide (NADH), fed into the ETC. ${ }^{23}$

The ETC is a source of reactive oxygen species (ROS), especially in renal cells, which have a large number of mitochondria. ${ }^{24}$ In diabetic kidney cells, highly stimulated, hyperpolarized mitochondria with high redox potential, produce increased levels of adenosine triphosphate (ATP) and superoxide anion $\left(\mathrm{O}_{2}^{-\bullet}\right)$ through the complexes I and II. $\mathrm{O} 2-\bullet$ originates both radical and non-radical RONS, including hydrogen peroxide $(\mathrm{H} 2 \mathrm{O} 2)$, the hydroxyl radical $(\bullet \mathrm{OH})$ and the ONOO-, which may be involved in the genesis of the lesions (Figure 1). ${ }^{25,26}$

In the kidney of diabetic or diabetic/obese individuals, mitochondrial energy, altered by hyperglycemia and hyperlipidemia, causes mitochondrial dysfunction and excess ROS, which are harmful to mitochondrial DNA (mtDNA) by inhibiting the mammalian target of rapamycin complex 1 (mTORC1) and the AMP-activated protein kinase (AMPK). These changes alter the activation of the peroxisome proliferator-activated receptor gamma coactivator 1-alpha (PGC-1 $\alpha$ ), and thereby affect mitochondrial biogenesis, by increasing mitochondrial fission and the synthesis of defective mitochondria. This can lead to impairment of the ECT functions, with reduced synthesis of ATP, leading to renal cell lesion and apoptosis. ${ }^{27}$

In addition, increased glycolysis causes hyperactivation of polyol and hexosamine metabolic pathways, and increases the synthesis of AGEs and activation of PKC. This also result in decreased ATP levels, contributing to mitochondrial dysfunction and fragmentation. ${ }^{28}$

\section{Polyol pathway}

One of the consequences of the increased glucose uptake by the cells is the increment in the NADPH-dependent conversion of glucose into sorbitol by aldose reductase. Sorbitol is then converted to fructose, by nicotinamide adenine dinucleotide (NAD). ${ }^{29,30} \mathrm{NADPH}$ is an important cofactor for regeneration of the antioxidant glutathione (GSH). Therefore, in light of increased aldose reductase activity, the low availability of NADPH affects the antioxidant defense, resulting in redox imbalance. ${ }^{31}$

The increase in $\mathrm{O} 2 \bullet$ - inhibits the activity of glyceraldehyde 3-phosphate dehydrogenase (GAPDH), which, in turn, inhibits glycolysis and activates alternative pathways. The increase in the NADH/NAD ratio increases the production of DAG, which activates PKC. Fructose, an end-product of the pathway, has been recently related to kidney injury markers. ${ }^{20}$

\section{Protein kinase C (PKC)}

Both hyperglycemia and increased stimulation of glycolysis by-products increase the synthesis of glyceraldehyde-3phosphate and its conversion into dihydroxyacetone, and thereby promote the synthesis of DAG, a PKC-activating factor (Figure 2). ${ }^{31}$ 


\section{Review Article}

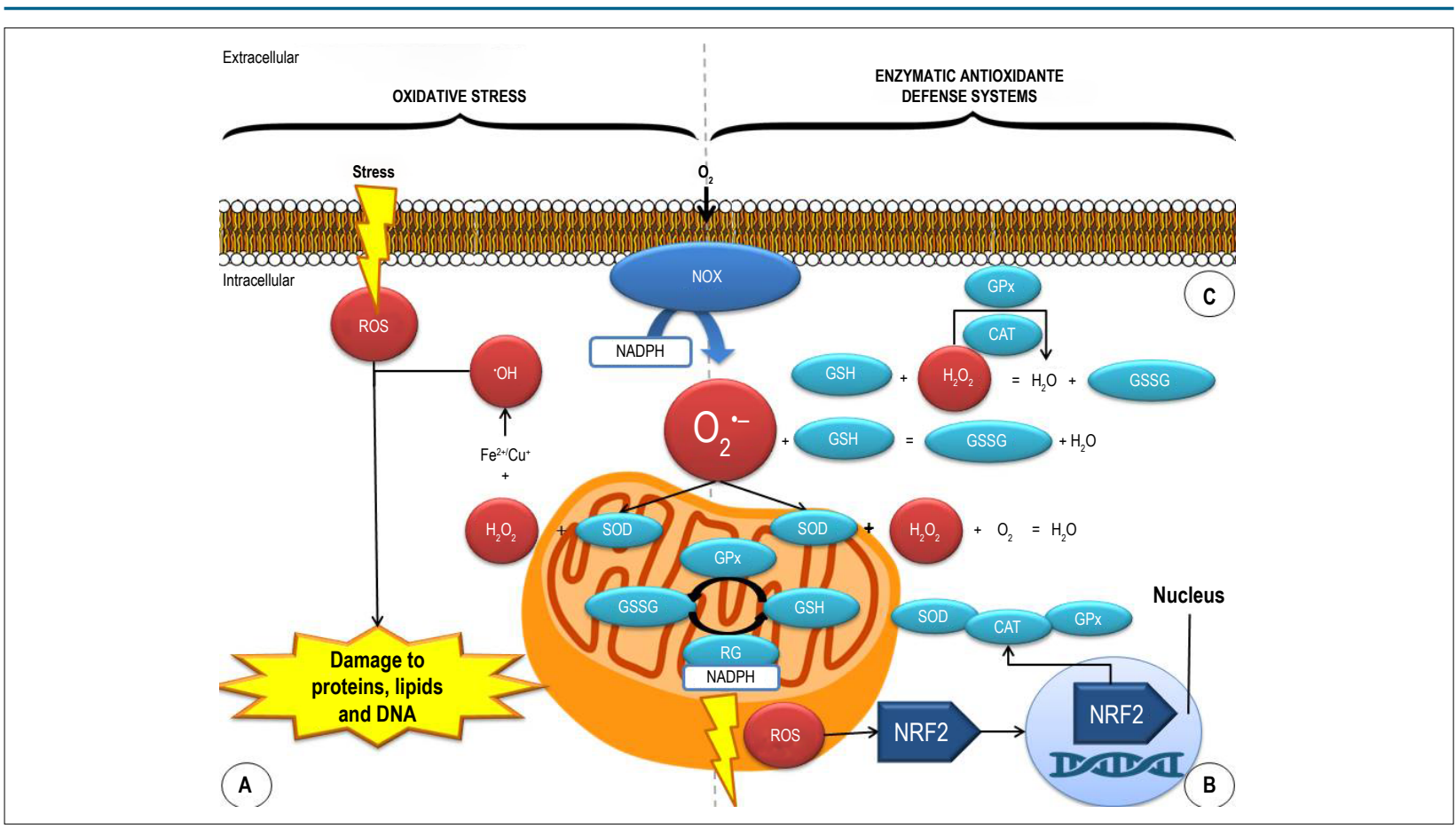

Figure 1 - Oxidative stress and enzymatic antioxidant defense system in diabetic renal cells. CAT: catalase; ROS: reactive oxygen species; GPx: glutathione peroxidase; GSH: glutathione; GSSG: oxidized glutathione; $R G$ : reduced glutathione; $\mathrm{H}_{2} \mathrm{O}_{2}$ : hydrogen peroxide; NRF2: nuclear erythroid 2-related factor 2; $\mathrm{O}_{2}$ : molecular oxygen; NOX: NADPH oxidase; $\mathrm{O}_{2} \because$ superoxide anion radical; ' $\mathrm{OH}$ : hydroxyl radical; $\mathrm{SOD}$ : superoxide dismutase. Adapted from Bhargava. ${ }^{28}$

In renal cells, increased PKC stimulates several mechanisms involved in the development of kidney injury. The induction and activation of endothelial nitric oxide synthase (eNOS) by $\mathrm{PKC}$ increases the availability of nitric oxide (NO) in diabetic kidney in the first stages of DKD. ${ }^{32}$ Increased NO contributes to elevation of prostaglandin E1 levels, Ang II activity, and activation of the vascular endothelial growth factor (VEGF), resulting in increased permeability, endothelial dysfunction, glomerular hyperfiltration and albuminuria. ${ }^{33,34}$

In prolonged diabetes, persistent hyperglycemia reduces the levels of tetrahydrobiopterin (BH4), an eNOS cofactor, with proportional reduction in NO synthesis in vascular endothelium, leading to vasoconstriction and glomerular and systemic hypertension. ${ }^{34}$

Hyperglycemia-related endothelial damage is caused by a nitroso-redox imbalance, by increased RONs (resulting from the interaction between $\mathrm{O} 2 \bullet-$ and $\mathrm{NO}$, which leads to increased ONOO- and decreased vascular $\mathrm{NO}$ ), leading to endothelial dysfunction and DKD progression. ${ }^{35}$

Increased expression of PKC leads to activation of the transforming growth factor-beta (TGF- $\beta$ ) and the plasminogen activator inhibitor-1 (PAI-1), resulting in increased deposition of fibronectin, collagen types I and IV and extracellular matrix deposition, and consequently, renal hypertrophy, glomerulosclerosis and renal fibrosis. ${ }^{30}$

\section{Hexosamines}

The hyperfunction of this pathway, stimulated by hyperglycemia, promotes the conversion of fructose 6-phosphate, and the synthesis of uridine diphosphate $\mathrm{N}$-acetylglucosamine (UDP-GlcNAc) as end product, which is $\mathrm{O}$-glycosylated into $\mathrm{N}$-acetylglucosamine $(\mathrm{O}-\mathrm{GlcNAc})$ by the O-GlcNAc transferase..$^{29,30}$

The excess of $\mathrm{O}-\mathrm{GlcNAc}$ is responsible for stimulating and modifying cell protein. In DKD, changes in genetic expression increase TNF- $\alpha$ transcription, thereby inducing renal damage via OS, and overproduction of extracellular matrix proteins. ${ }^{20,29,36}$

\section{Advanced glycation end products (AGEs)}

AGEs are uremic toxins and their involvement in the development of renal damage may be partially explained by increased endogenous synthesis resulting from hyperglycemia, diet and insufficient clearance of these products due to reduced GFR. ${ }^{37}$

AGEs are formed through non-enzymatic amino-carbonyl reactions, or Maillard reaction between the carbonyl group of glucose, fructose, galactose and ribose, or intermediates of glucose metabolism (glucose-6-phosphate, fructose-6phosphate, ribose-5-phosphate, deoxyribose-5-phosphate and glyceraldehyde), with an amine group and other molecules, to form a reversible Schiff base, and subsequently, Amadori products, which are initial products of the Maillard reaction. ${ }^{13}$ Synthesis of the Amadori products is accelerated in hyperglycemic conditions, and these compounds are highly reactive with amine groups and metal ions through glycoxidation of biological molecules, forming glyoxal (GO), methylglyoxal (MGO), and malondialdehyde (MDA). ${ }^{38,39}$ 


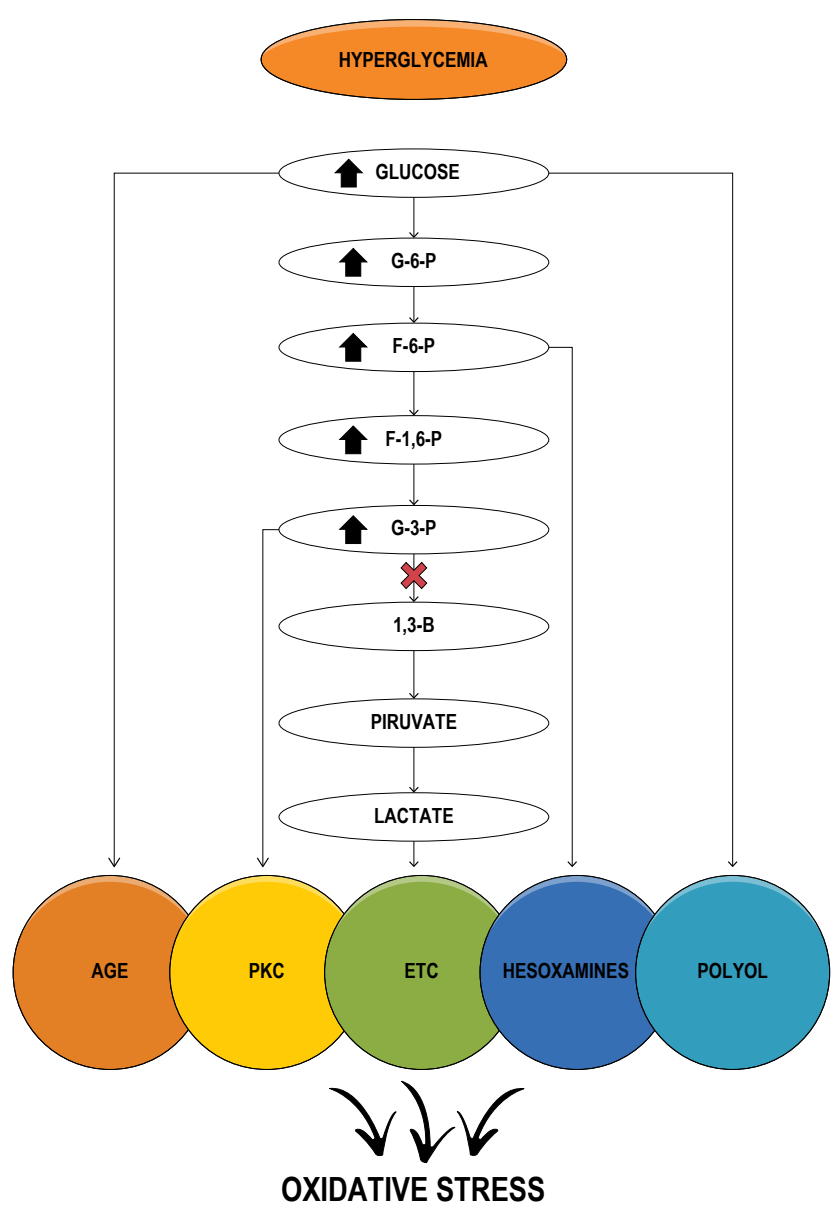

Figure 2 - Schematic representation of the pathways preceding glycolysis and induction of oxidative stress. ETC: electron transport chain; 1,3-BPG: bisphosphoglycerate; G6P: glucose 6-phosphate; G3P: glyceraldehyde-3-phosphate; GAPDH: glyceraldehyde-3-phosphate dehydrogenase; F6P: fructose-6-phosphate; F-1,6-P: fructose-1,6phosphate; PKC: protein kinase C; AGE; advanced glycation end-products

After AGEs' metabolism and removal from the tissues, the low molecular weight, soluble peptides and the second generation AGEs need to be excreted in the urine. Second generation AGEs can be highly reactive products, but their effects are limited by renal excretion. However, in renal failure, AGEs excretion is impaired, contributing to the increased levels in serum and tissues. ${ }^{38}$

Such increase in the endogenous pool of AGEs causes direct damage to the cells by interaction of extracellular proteins with cellular components (proteins, carbohydrates, lipids and nucleotides), affecting cellular structure and functions. These modified proteins have decreased enzymatic hydrolysis, resulting in excessive accumulation of extracellular matrix proteins, glomerulosclerosis, and consequently, renal fibrosis. ${ }^{34}$

In addition to direct extra- and intracellular damage, AGEs interact with their transmembrane receptor - the receptor for advanced glycation end products (RAGE), which are expressed in many types of renal and inflammatory cells. ${ }^{40}$ Following the substrate/receptor interaction, a cascade of reactions inside the cell is initiated. These reactions regulate the transcription of proteins, adhesion molecules and proinflammatory cytokines, such as IL-1, IL-6 e TNF- $\alpha$, mediated by the activation of macrophages via NF- $\kappa B$, exacerbating subclinical tissue inflammation associated with DM in DKD. ${ }^{41,42}$

The AGEs/RAGEs interaction is associated with increased production of RONs; it contributes to the OS by direct activation of NOX (by mitochondrial activation through the RAGEs in renal cells and infiltrated immune cells). Also, AGs reduces the expression of eNOS and increases the expression of inducible NOS (iNOS), triggering OS by increased $\mathrm{ONOO}^{-}$production and reducing $\mathrm{NO}$ availability. Consequently endothelial dysfunction occurs by synthesis of vascular cell adhesion molecule 1 (VCAM-1), intercellular adhesion molecule 1 (ICAM-1), monocyte chemotactic protein-1 (MCP-1) and TGF- $\beta .^{38,39}$

\section{NADPH-oxidases}

The NOX family of NADPH oxidases is an important source of ROS in DM. There are seven different NOX isoforms: NOX1, NOX2, NOX3, NOX4 (formerly known as "renox" due to its high expression in renal tissue), NOX5 and the 
dual oxidases 1 and 2 (DUOX1 and DUOX2, respectively). ${ }^{9}$ NADPH oxidases are transmembrane proteins responsible for transferring electrons from cytosolic $\mathrm{NADPH}$ to the $\mathrm{O}_{2}$, which is reduced to $\mathrm{O}_{2}{ }^{\circ}$, thereby perpetuating the oxidative stress state in renal cells. ${ }^{9,25}$

NOX-derived ROS regulate physiological processes in the kidneys. However, they are upregulated in hyperglycemic renal cells, and abnormally activated by AGEs, PKC, TGF $\beta$ and Ang II, resulting in $\mathrm{O}_{2}{ }^{--}$overproduction and accumulation. $\mathrm{O}_{2}{ }^{\cdot-}$ acts as an important mediator of redox imbalance and damage to different kidney cell components. ${ }^{9,43}$

\section{Angiotensin II}

Chronic hyperglycemia in DM induces increased synthesis of Ang II and its receptors by glomerular and mesangial cells, and podocytes. It increases the expression of renin and angiotensinogen in mesangial cells, elevating intrarenal angiotensin levels. This mechanism is exacerbated by ROS accumulation in adipose tissue, where Ang II is produced. ${ }^{34,44}$

Elevations of Ang II contribute to abnormal activation of the renin-angiotensin-aldosterone system (RAAS), aggravating mechanical damages induced by systemic and intraglomerular hypertension in the kidney. Additional effects of Ang II include direct mediation in RON production, early hyperplasia and late hypertrophy of renal cells, by stimulation of TGF- $\beta$, IL-6 and MCP-1, and activation and upregulation of NF- $\mathrm{\kappa B} .{ }^{45}$

\section{Hemodynamic changes in diabetic kidney damage}

Early DKD is marked by changes in renal hemodynamics caused by hyperglycemia. ${ }^{46}$ The initial hemodynamic events are characterized by glomerular hyperperfusion, hypertension and hyperfiltration, and responsible for functional and structural changes in the glomeruli, resulting in albuminuria, increase followed by decrease of GFR, glomerular hypertrophy, mesangial expansion, podocyte injury, glomerulosclerosis and renal fibrosis, and natural history DKD. ${ }^{47,48}$

Hypertension commonly precedes DKD, especially in DM2. However, persistent metabolic disturbances cause sustained hypertension, and dysregulation of pressure levels, inducing and/or aggravating diabetic kidney injury. ${ }^{45}$ The mechanism of hypertension in DKD is complex, multifactorial, and involves altered sodium regulation, such as renal tubular reabsorption of sodium, abnormal activation of the RAAS and of sympathetic nervous system (SNS), endothelial cell dysfunction, and increased OS. These processes mediate vasoconstriction and increase extracellular volume with consequent increase in blood pressure. ${ }^{49,50}$

Among hemodynamic factors that contribute to hypertension and renal hyperfiltration, RAAS has been the most widely accepted for the development of DKD, and its blockade has shown to delay the progression of the disease. ${ }^{51}$ Mechanical stress on vascular wall induced by hypertension, hyperglycemia, inflammation and ROS considerably increase Ang II production in renal cells and contribute to RAAS hyperactivation. ${ }^{45,51}$ This in turn, contributes to systemic and renal vascular vasoconstriction, and renal reabsorption of sodium via interaction with Ang II receptor type 1 (AT1) and aldosterone release, leading to elevations in blood pressure, intraglomerular pressure and renal damage..$^{52}$
The effects of Ang II on redox imbalance (additional effects of Ang II on inflammation and redox imbalance, and important factors in the pathophysiology of DKD are described above) via production of $\mathrm{O} 2 \cdot-$ by local NOXs induce endothelial dysfunction (due to an imbalance between vasoconstrictor and vasodilator factors). ${ }^{53}$ In response to increased ROS, there is a reduction in the synthesis of $\mathrm{NO}$, a potent vasodilator that interacts with the substrate $\mathrm{BH} 4$, reducing eNOS activity. Besides, there is a direct effect of the $\mathrm{O}^{-}{ }^{-}$on reducing $\mathrm{NO}$ and $\mathrm{ONOO}^{-}$, and reducing $\mathrm{NO}$ availability, leading to sustained vasoconstriction. ${ }^{50}$

The actions of Ang II, in addition to endothelial dysfunction, vasoconstriction and vascular resistance, induced by the OS, result in elevations in the pressure of afferent arterioles, which, in turn, cause an increase in systemic blood pressure, glomerular hyperperfusion and hyperfiltration, and proteinuria, leading to progressive DKD. ${ }^{50}$

In addition, sodium-hydrogen exchangers (NHEs) play an important role on renal and systemic hemodynamics in DKD. NHEs are expressed in different types of renal cells and regulate sodium $\left(\mathrm{Na}^{+}\right)$and hydrogen $\left(\mathrm{H}^{+}\right)$transport, essential for different cell functions, including maintenance of intracellular $\mathrm{pH}$, fluid volume and cell survival..$^{54}$ In the kidneys, particularly in tubular cells and macula densa cells, NHE isoforms 1, 2 and 3 (NHE1, NHE2 and NHE3, respectively) play an important role in the pathogenesis of DKD, by inducing intraglomerular hypertension and mesangial proliferation, and by promoting of inhibiting programmed cell death (apoptotic factors), contributing to renal fibrosis. ${ }^{55}$

In macula densa cells, the NHE2 receptors are involved in the regulation of renin and salt sensors. The suggested mechanism is that cell shrinkage (induced by hypertonicity), together with Ang II, is the renin-release signal, leading to the overexpression of the RAAS and increase in intraglomerular pressure. This would activate the signaling pathway that results in increased expression of the NHE receptors in renal cells (promoting a vicious circle). ${ }^{56}$ Also, salt excess, induced by $\mathrm{NHE}$ in the macula densa, causes an increase in intracellular $\mathrm{pH}$ and cell depolarization, leading to activation of ROS synthesis by the NOX enzymes. ${ }^{57}$

NHEs are targets of many drug therapies, including inhibitors of the RAAS and of SGLTs, which are involved in NHE blockade in the kidneys, contributing to reduction of intraglomerular pressure, and of proliferative and fibrotic processes. ${ }^{56}$

Blockade of the RAAS and Ang II with angiotensinconverting enzyme inhibitors and Ang II receptor blockers (either combined or alone), have shown to be effective in reducing proteinuria and delaying the progression of DKD by their hemodynamic/anti-hypertensive, anti-inflammatory and antifibrotic effects, and hence could be used to improve the prognosis of DKD patients. ${ }^{58}$

\section{Redox imbalance in DKD}

OS is the first stage of DKD and activates pathological pathways in practically all types of renal cells, including endothelial, mesangial, epithelial, tubular cells and podocytes. ${ }^{19}$ OS results from an imbalance in which the increase in RONs overwhelms the lower efficient (enzymatic and non-enzymatic) antioxidant system, leading to the redox imbalance between pro- and antioxidants. ${ }^{59,60}$ 
The generation of RONs occurs in many types of cells in the kidneys and infiltrating cells, such as immune cells, neutrophils and macrophages. A substantial increase in glucose auto-oxidation, combined with greater ETC activation and mitochondrial stress, is accompanied by increased RON production, accounting for nearly $80 \%$ of all reactive species. ${ }^{25,61}$ In addition to these pathways, other enzymatic systems, such as uncoupled eNOS and NOXs, and non-enzymatic systems, such as Ang II, are involved in ROS generation in the kidney of diabetic patients and obese diabetic patients. ${ }^{62}$

The overproduction of RON induced by hyperglycemia reduces the expression of antioxidant enzymes, including the superoxide dismutase (SOD) (particularly the manganese SOD subtype that acts in the mitochondria), thioredoxin reductase, and catalase (CAT), and decreases regeneration of reduced glutathione (GSH) by activation of the polyol pathway. In addition, spontaneous reduction of non-enzymatic antioxidants occurs in consequence of increased ROS in response to increased demand. ${ }^{63}$ The SOD is considered the main physiological defense against ROS, as it initiates the enzymatic antioxidant defense by reacting with $\mathrm{O} 2 \cdot \cdot$ to form $\mathrm{H}_{2} \mathrm{O}_{2}$, which will be degraded by CAT and GPx (Figure 1). ${ }^{21,59}$

In low concentrations, RONs modulate transcription factors of antioxidant enzymes, essential for OS attenuation. Among these transcription factors, there is the nuclear erythroid 2-related factor 2 (NRF2), which translocate to the nucleus to activate the transcription of genes responsible for codifying antioxidant enzymes like SOD, CAT and GPx, thereby suppressing the NF-kB activity. However, in ROS overproduction, as found in DM, these defenses are not effective in blocking or preventing the establishment of the redox imbalance. ${ }^{64}$

In diabetic kidney, RONs decreases the expression of sirtuins (SIRT), enzymes responsible or modulating the regeneration of antioxidants via acetylation of the ETC, essential for the stimulation of mitochondrial SOD and induction of transcription factors, (such as the PGC1- $\alpha$ ), attenuating mitochondrial stress and NRF2 activation. ${ }^{62}$ Also, the O-GlcNAc, product of hexosamines, attenuates the SIRT activity, contributing to exacerbation of this process in DM. ${ }^{63}$ In the kidney of diabetic rats, reduced expression of PGC- $1 \alpha$, a regulator of oxidative metabolism and mitochondrial biogenesis, has been associated with higher production of RONs by aggravating mitochondrial dysfunction and fragmentation. ${ }^{65}$

A gradual decrease in the antioxidant defenses in chronic kidney disease has been described in vivo, opening a new field of treatment. ${ }^{66}$ Recent studies have shown the efficacy of high antioxidant intake as an adjuvant in the treatment of DKD, by helping in both enzymatic and non-enzymatic antioxidant defense against harmful compounds. ${ }^{67}$

In a recent meta-analysis, Bolignano et al. ${ }^{68}$ evaluated 14 studies (4,345 participants) for the effects of antioxidant supplementation (including vitamin $\mathrm{C}$, vitamin $\mathrm{E}$ and zinc, either combined or alone) on DKD disease progression and markers of renal function. The authors concluded that the antioxidant therapy significantly decreased albuminuria, but apparently had no tangible effect on renal function in patients with diabetic kidney disease. Stronger evidence of benefits was found for vitamin $\mathrm{E}$ at doses varying from $480 \mathrm{mg}$ to $1,200 \mathrm{mg} /$ day.

Experimental studies on vitamin and mineral supplementation, such as vitamin D, vitamin $E$ and zinc, have shown favorable results in reducing renal failure, inflammation and OS. ${ }^{67-70}$ Besides, phenolic compounds and flavonoids have shown beneficial effects as therapeutic agents in the treatment of DKD in cells and animals. ${ }^{71}$

Immunological disorders in DKD: the role of inflammation

DKD has been associated with systemic and intrarenal inflammation. Persistent metabolic and hemodynamic stimuli in diabetic kidney result in cell lesion that releases molecules known DAMPs - danger-associated molecular pattern including PGAs, ROS, FFAs. These compounds interact with pattern recognition receptors, including Toll-like receptors 2 and 4 and RAGE, positively regulated by hyperglycemia. In the presence of DAMPs/receptors interaction, the intrarenal innate immune response is activated. ${ }^{5}$

The myeloid lineage of innate immune cells causes renal inflammation in diabetic conditions, with involvement of several immune cells in the pathogenesis and severity of renal damage. However, pro-inflammatory factors released in diabetic renal tissue include not only infiltrating inflammatory cells, but also cytokines and chemokines found in non-immune cells, such as in parenchymal cells (podocytes, and endothelial, epithelial, mesangial and tubular cells), exacerbating the inflammatory process that leads to progressive damages in DKD (Chart 1). ${ }^{19}$

In addition, the binding of DAMPs with their receptors has been associated with activation of molecular and transcription factors that promote activation of NF- $\kappa \mathrm{B}$, facilitating the expression of many pro-inflammatory genes (cytokines, chemokines, adhesion molecules, immune receptors and growth factors). Consequently, NF- $\kappa$ B has been considered a master regulator of immune responses and inflammation in DKD. ${ }^{26,72}$

The main proinflammatory cytokines are IL-1, IL-6, IL18 and TNF- $\alpha$; all of them have autocrine, paracrine and juxtacrine mechanisms with pleiotropic effects that regulate the expression of cytokines, interleukins, TNF- $\alpha$, interferons, growth factors, adhesion molecules and nuclear transcription factors, promoting the increase and perpetuation of inflammation and OS in diabetic kidney (Chart 1). ${ }^{73,74}$

Intracellular metabolic changes with increased AGEs and ROS lead to increased release of MCP-1, which promotes the activation of monocytes and macrophages. These, in turn, are associated with increased expression of adhesion molecules and synthesis of pro-inflammatory cytokines, leading to hyperfiltration and glomerular lesions, typical of DKD. ${ }^{75,76}$

Due to its close relationship with obesity, kidney damage of patients with type $2 \mathrm{DM}$ is associated with early activation of the immune system, which is related to chronic, low-grade systemic inflammation induced by adipose tissue. ${ }^{44,50}$ 


\section{Review Article}

Chart 1 - Inflammatory cytokines and their effects on renal function in diabetes mellitus

\begin{tabular}{|c|c|c|c|c|c|c|}
\hline Cytokines & Stimulated by & Specialized producing cells & $\begin{array}{l}\text { Exerts positive } \\
\text { effects on }\end{array}$ & Effects on DKD & $\begin{array}{l}\text { Target cells in } \\
\text { the kidneys }\end{array}$ & Ref. \\
\hline $\begin{array}{l}\text { IL-1a, } \\
\text { IL-1 } 1 \beta\end{array}$ & $\begin{array}{l}\text { Inflammasome } \\
\text { IL-18 and NF-KB }\end{array}$ & $\begin{array}{c}\text { Macrophages, Granulocytes* } \\
\text { Tubular epithelial Endothelial, } \\
\text { Mesangial }^{\dagger} \\
\text { Fibroblasts }^{\ddagger}\end{array}$ & $\begin{array}{c}\uparrow \text { ICAM-1, } \\
\uparrow \text { VCAM- } 1, \\
\uparrow \text { Prostaglandin E2 }\end{array}$ & $\begin{array}{c}\uparrow \text { Intraglomerular hemodynamic } \\
\text { abnormality, } \\
\uparrow \text { Synthesis of hyaluronic acid, } \\
\uparrow \text { Proliferation of mesangial cells } \\
\text { and fibroblasts, } \\
\uparrow E C M \text { accumulation }\end{array}$ & $\begin{array}{l}\text { Epithelial, } \\
\text { Mesangial, } \\
\text { Tubular }\end{array}$ & {$[77,83]$} \\
\hline IL-6 & $\begin{array}{l}\text { Hyperglycemia, AGEs, } \\
\text { TNF-a, LPS, IL-1, IL-4 }\end{array}$ & $\begin{array}{c}\text { T lymphocytes, Macrophages, } \\
\text { Neutrophils }{ }^{*} \\
\text { Endothelial, Podocytes, } \\
\text { Mesangial, Tubular epithelial }{ }^{\dagger} \\
\text { Fibroblasts }^{\ddagger}\end{array}$ & $\begin{array}{c}\uparrow \text { MCP-1, } \\
\uparrow \text { expression of Ang } \\
\text { II receptors, } \\
\uparrow \text { ROS }\end{array}$ & $\begin{array}{c}\uparrow \text { Recruitment of monocytes, } \\
\uparrow \text { Differentiation of macrophages, } \\
\uparrow \text { Synthesis of fibronectin, } \\
\uparrow \text { Synthesis and accumulation } \\
\text { of ECM, } \\
\uparrow \text { Mesangial cell proliferation, } \\
\uparrow \text { Endothelial dysfunction } \\
\uparrow \text { Tubulointerstitial fibrosis }\end{array}$ & $\begin{array}{l}\text { Mesangial, } \\
\text { Podocytes, } \\
\text { Endothelial, } \\
\text { Tubular } \\
\text { epithelial }\end{array}$ & {$[84,85]$} \\
\hline IL-18 & $\begin{array}{l}\text { NF-kB, } \\
\text { Inflammasome, } \\
\text { Caspase-1 }\end{array}$ & $\begin{array}{l}\text { T lymphocytes and } \\
\text { Macrophages }^{*} \\
\text { Epithelial, Tubular }{ }^{\dagger}\end{array}$ & $\begin{array}{c}\uparrow \text { IFN- } \gamma, \\
\uparrow I L-1, \text { IL-6, TNF-a, } \\
\text { iNOS, ICAM-1, } \\
\text { TGF- } \beta, \text { MCP- } 1\end{array}$ & $\begin{array}{c}\uparrow \text { Apoptosis of endothelial cells, } \\
\uparrow \text { infiltration off macrophages and } \\
\text { neutrophils }\end{array}$ & $\begin{array}{l}\text { Endothelial, } \\
\text { Tubular } \\
\text { epithelial }\end{array}$ & {$[30,86,87]$} \\
\hline TNF- $a$ & NF-kB & $\begin{array}{c}\text { Dendritic, Monocytes, } \\
\text { Macrophages, T lymphocytes* }\end{array}$ & $\begin{array}{c}\uparrow \text { Immune response } \\
\uparrow \mathrm{NF-kB}\end{array}$ & $\begin{array}{c}\uparrow \text { Inflammatory cells, cell } \\
\text { infiltration } \\
\uparrow \text { Citotoxicity, apoptosis, } \\
\uparrow \text { Endothelial permeability, } \\
\downarrow \text { Capillary wall barrier function, } \\
\uparrow \text { PKC, } \\
\uparrow N O X, \\
\uparrow \mathrm{ROS} ; \\
\uparrow \mathrm{ECM}\end{array}$ & $\begin{array}{l}\text { Mesangial, } \\
\text { Podocytes, } \\
\text { Endothelial, } \\
\text { Glomerular; } \\
\text { Tubular } \\
\text { epithelial }\end{array}$ & {$[19,78,83]$} \\
\hline
\end{tabular}

${ }^{*}$ Infiltrating immune cells; ${ }^{\dagger}$ Renal cells; ${ }^{\ddagger}$ Other cell types. Ang II: angiotensin 2; ROS: reactive oxygen species; TNF- $\alpha$ : tumor necrosis factors alfa; NF-KB: nuclear

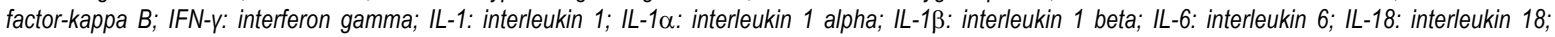
IL-4: interleukin 4; LPS: lipopolysaccharide; ICAM-1: intercellular adhesion molecule 1; VCAM-1: vascular cell adhesion molecule; ECM: extracellular matrix; NOX: NADPH oxidase; AGE: advanced glycation end-products; MCP-1: monocyte chemoattractant protein; PKC: protein kinase C; iNOS: nitric oxide synthase; TGF- $\beta$ : transforming growth factor-beta

Redox imbalance and inflammation in DKD: a vicious circle

Several hemodynamic and metabolic pathways are involved in the pathogenesis of DKD. In a common pathway, the interrelation between redox imbalance and inflammation induced by hyperglycemia occurs by mechanisms that involves cellular and molecular processes in a cascade of bioenergetic changes, promoting changes in extracellular, cellular and mitochondrial morphology, genetic expression modulation, induction of lesions, tissue hypertrophy, and renal fibrosis and necrosis (Figure 3). ${ }^{74}$

Inflammation is mediated by the upregulation of NF$\kappa \mathrm{B}$ expression by OS, AGEs and TNF- $\alpha$, which controls the immune response by stimulating genetic expression of pro-inflammatory cytokines, adhesion molecules, NOS, cell proliferation and progression of the inflammatory cycle and OS. ${ }^{77,78}$ ROS and the AGE-RAGE interaction, stimulated by DM-related hyperglycemia, act as mediators of the multiprotein complex inflammasome Nlrp, which regulates the cleavage of pro-inflammatory cytokines from the mature, active forms into innate immune cells, renal endothelial cells, glomerular cells and podocytes. ${ }^{79}$

The upregulation of pro-inflammatory cytokines (IL-1, IL-6, IL-18, IFN- $\gamma$ ), mediated by AGE/RAGE, TNF- $\alpha$ and NF- $\kappa$ B, causes an increase in RONs and transcription factors (Chart 1), which lead to local and systemic inflammation, glomerular and tubular lesions, and ultimately, albuminuria. ${ }^{80}$ Among the cytokines, TNF- $\alpha$ is known to cause direct cytotoxicity and apoptosis of renal cells. ${ }^{17} \mathrm{~A}$ recent meta-analysis showed a statistically significant increase in serum concentrations of TNF- $\alpha$ in type 2 DM patients, especially in those with DKD, suggesting that increased inflammatory load in DKD contributes to disease progression. ${ }^{81}$

The expression of profibrotic transcription factors, such as the TGF- $\beta$ and connective tissue growth factor, triggers the recruitment of extracellular matrix-producing cells, accelerating renal sclerotic and fibrotic processes. ${ }^{9}$ TGF- $\beta$ plays pleiotropic effects, promoting hyperplasia and hypertrophy of renal cells. In the extracellular matrix, TGF- $\beta$ is found in a latent form, bound to proteins, requiring cleavage to release of its free, active form. This activation is performed by mediators produced under hyperglycemic condition, including AGEs, ROS, DAG, PKC, Ang II, among others. Once activated, TGF- $\beta$ binds to its cell receptor, and regulates the transcription of target genes, including collagen types I, III and IV, fibronectin, plasminogen, and PAI-I, with net effect of protein synthesis and expansion of the extracellular matrix, glomerulosclerosis and renal fibrosis. It also activates NF- $\kappa \mathrm{B}$, contributing to the production of proinflammatory cytokines, exacerbating local inflammation. ${ }^{34,74,82}$ 


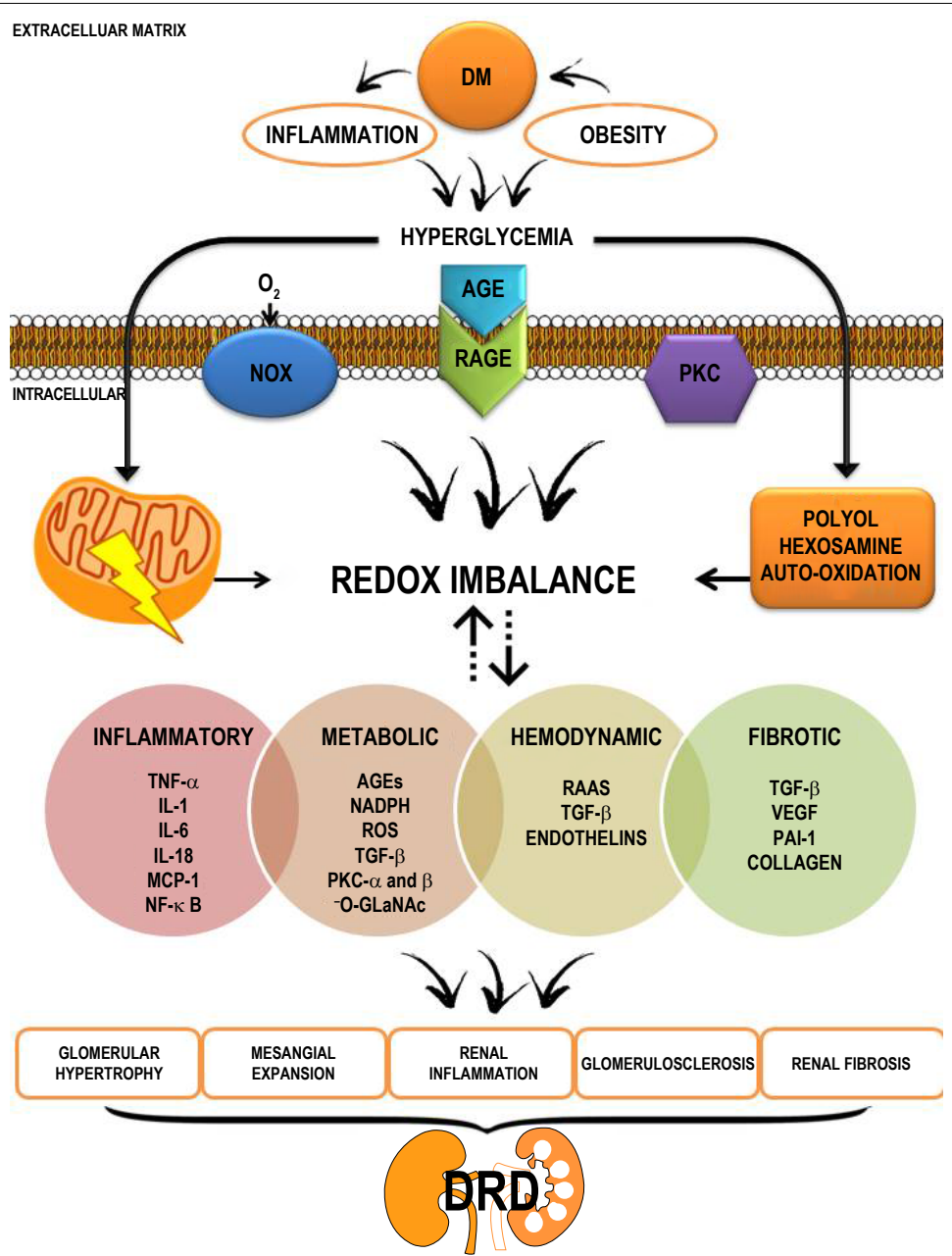

Figure 3 - Mediators of kidney injury induced by chronic hyperglycemia via redox imbalance and inflammation in the pathogenesis of diabetic kidney disease. ROS: reactive oxygen species; ERK: extracellular signal-related kinases; TNF- $\alpha$ : tumor necrosis factor alpha; NF-KB: nuclear factor-kappa B; VEGF: the vascular endothelial growth factor; IL-1: interleukin 1; IL-6: interleukin 6; IL-18: interleukin 18; ECM: extracellular matrix; NOX: NADPH oxidase; O-GLaNAc: 0-glycosylated into $\mathrm{N}$-acetylglucosamine; PAl-1: plasminogen activator inhibitor-1; AGE: advanced glycation end-products; PKC: protein kinase C; MCP-1: monocyte chemotactic protein-1; RPGA: receptor for advanced glycation end products; RAAS: renin-angiotensin aldosterone system; TGF- $\beta$ : transforming growth factor-beta.

\section{Conclusion}

Recently, there has been increasing evidence that redox imbalance and inflammation in response to intermittent or chronic exposure to hyperglycemia play an important role in initiation and perpetuation of DM complications, including DKD. They are now considered the main contributors to the development of DKD and end-stage kidney disease. New pathological pathways, associated with renal dysfunction in DM and that particularly exacerbate metabolic pathways, have been identified, such as the association between DKD and obesity. Therefore, metabolic, inflammatory and oxidative interference of DM and other risk factors for DKD should be continuously investigated and updated not only to improve the understanding of the mechanisms, but also to determine new therapeutic targets.

\section{Acknowledgment}

The present work was carried out with the support of the Coordenação de Aperfeiçoamento de Pessoal de Nível Superior - Brasil (CAPES) - Financing Code 001.

\section{Author contributions}

Conception and design of the research: Santos JCF, Amorim RG, Vasconcelos S; Writing of the manuscript and Critical revision of the manuscript for intellectual content: Santos JCF, Amorim RG, Guedes GS, Vasconcelos S.

\section{Potential Conflict of Interest}

No potential conflict of interest relevant to this article was reported.

\section{Sources of Funding}

There were no external funding sources for this study.

\section{Study Association}

This article is part of the thesis of master submitted by Rayne Gomes Amorim, from Pós-graduação em Nutrição da Universidade Federal de Alagoas. 


\section{Review Article}

\section{Erratum}

In review article "Kidney Disease in Diabetes Mellitus: Cross-Linking between Hyperglycemia, Redox Imbalance and Inflammation", consider Sandra Mary Lima Vasconcelos as the correct form for the name of the author Sandra Mary de Lima Vasconcelos.

\section{References}

1. Sociedade Brasileira de Diabetes.Sociedade Brasileira de Nefrologia. Posicionamento Oficial Tripartite n. 01/2016. Prevenção, Diagnóstico e Conduta terapêutica na doença renal do diabetes [Internet] (Acesso em 2018 jan 100. Disponível em : https://www.diabetes.org.br/ profissionais/images/pdf/posicionamento.sbd-sbem-sbn.pdf:sbdsbem-sbn.pdf

2. Levin A, Stevens PE, Bilous RW, Coresh J, De Francisco ALM, De Jong, PE, et al. Kidney disease: Improving global outcomes (KDICO) CKD work group. KDIGO 2012 clinical practice guideline for the evaluation and management of chronic kidney disease. Kidney Int Suppl. 2013;3(1):1-150.

3. International Diabetes Federation. IDF Diabetes Atlas. 8th. ed. Brussels: International Diabetes Federation; 2017.

4. Chatterjee S, Khunti K, Davies MJ. Type 2 diabetes. Lancet. 2017; 389(10085):2239-51.

5. Tesch GH. Diabetic nephropathy - is this an immune disorder?. Clin Sci. 2017;131(16):2183-99.

6. American Diabetes Association (ADA). 1. Improving care and promoting health in populations: standards of medical care in diabetes-2018. Diabetes Care. 2018;41(Suppl 1):S7-12.

7. Turkmen K. Inflammation, oxidative stress, apoptosis, and autophagy in diabetes mellitus and diabetic kidney disease: the Four Horsemen of the Apocalypse. Int Urol Nephrol. 2017;49(5):837-44.

8. Reidy K, Kang HM, Hostetter T, Susztak K. Molecular mechanisms of diabetic kidney disease. J Clin Invest. 2014;124(6):2333-40.

9. Jha JC, Banal C, Chow BSM, Cooper ME, Jandeleit-Dahm K. Diabetes and kidney disease: role of oxidative stress. Antioxid Redox Signal. 2016;25(12):657-84

10. Silva TA, Vasconcelos SML. O controle da glicemia como um fator atenuante do estresse oxidativo da hipertensão arterial. Rev Bras Hipertens. 2011;18(3):113-5.

11. Kwon H, Pessin JE. Adipokines mediate inflammation and insulin resistance. Front Endocrinol. 2013 Jun 12;4:71.

12. De Luca C, Olefsky JM. Inflammation and insulin resistance. FEBS Lett. 2008;582(1):97-105.

13. Santos JC de F, Valentim IB, de Araújo ORP, Ataide TR, Goulart MOF. Development of nonalcoholic hepatopathy: Contributions of oxidative stress and advanced glycation end products. Int J Mol Sci. 2013;14(10):19846-66.

14. Queiroz JC, Alonso-Vale MI, Curi R, Lima FB. Control of adipogenesis by fatty acids. Arq Bras Endocrinol Metabol. 2009;53(5):582-94.

15. Freitas MC, Ceschini FL, Ramallo BT. Insulin resistance associated with obesity: anti-inflammatory effects of physical exercise. R Bras Ci Mov. 2014;22(3):139-47.

16. Lagranha $C$ J, Fiorino $P$, Casarini $D E$, Schaan $B D$, Irigoyen MC. Molecular bases of diabetic nephropathy. Arq Bras Endocrinol Metabol. 2007;51(6):901-12.

17. Machado UF, Schaan BD, Seraphim PM. Glucose transporters in the metabolic syndrome. Arq Bras Endocrinol Metabol. 2006;50(2):177-89.

18. Vallon $\mathrm{V}$. The proximal tubule in the pathophysiology of the diabetic kidney. Am J Physiol Regul Integr Comp Physiol. 2011;300(5):R1009-22.
19. Donate-Correa J, Martín-Núñez E, Muros-de-Fuentes M, Mora-Fernández C, Navarro-González JF. Inflammatory cytokines in diabetic nephropathy. J Diabetes Res. 2015:2015:948417.

20. Toth-Manikowski S, Atta MG. Diabetic kidney disease: pathophysiology and therapeutic targets. J Diabetes Res. 2015;2015:697010.

21. Barbosa KBF, Costa NMB, Gonçalves RC, De Paula SO, Minim VPR, Bressan J. Oxidative stress: concept, implications and modulating factors. Rev Nutr. 2010;23(4):629-43.

22. Barreiros ALBS, David JM, David JP. Estresse oxidativo: Relação entre geração de espécies reativas e defesa do organismo. Quim Nova. 2006;29(1):113-23.

23. Higgins GC, Coughlan MT. Mitochondrial dysfunction and mitophagy: the beginning and end to diabetic nephropathy? Br J Pharmacol. 2014;171(8):1917-42.

24. Che R, Yuan Y, Huang S, Zhang A. Mitochondrial dysfunction in the pathophysiology of renal diseases. Am J Physiol Renal Physiol. 2014;306(4):F367-78

25. Sharma K. Obesity and diabetic kidney disease: role of oxidant stress and redox balance. Antioxid Redox Signal. 2016;25(4):208-16.

26. Levin A, Djurdjev O. On being better kidney doctors: understanding trajectories, probabilities, predictability, and people. Am J Kidney Dis. 2012;59(4):475-7.

27. Han Q, Zhu H, Chen X, Liu Z. Non-genetic mechanisms of diabetic nephropathy. Front Med. 2017;11(3):319-32.

28. Bhargava P, Schnellmann RG. Mitochondrial energetics in the kidney. Nat Rev Nephrol. 2017;13(10):629-46.

29. Reis JS, Veloso CA, Mattos RT, Purish S, Nogueira-Machado JA. Oxidative stress: a review on metabolic signaling in type 1 diabetes. Arq Bras Endocrinol Metab. 2008;52(7):1096-105.

30. Aghadavod E, Khodadadi S, Baradaran A, Nasri P, Bahmani M, RafieianKopaei M. Role of oxidative stress and inflammatory factors in diabetic kidney disease. Iran J Kidney Dis. 2016;10(6):337-43.

31. Blacker TS, Duchen MR. Investigating mitochondrial redox state using NADH and NADPH autofluorescence. Free Radic Biol Med. 2016 Nov;100:53-65.

32. Geraldes $P$, King LG. Activation of protein kinase $C$ isoforms and its impact on diabetic complications. Circ Res. 2010;106(8):1319-31.

33. Noh H, King GL. The role of protein kinase $\mathrm{C}$ activation in diabetic nephropathy. Kidney Int Suppl. 2007 Aug; (106):S49-53.

34. Kanwar YS, Sun L, Xie P, Liu F, Chen S. A Glimpse of various pathogenic mechanism of diabetic nephropathy. Annu Rev Pathol. 2011;6:395-423.

35. Takahashi T, Harris RC. Role of endothelial nitric oxide synthase in diabetic nephropathy: lessons from diabetic eNOS knockout mice. J Diabetes Res. $2014 ; 2014: 590541$.

36. Lima V L. Papel da O-glicosilação com N-acetil-glucosamina (O-GlcNAc) nas alterações vasculares associadas a altos níveis de endotelina-1 [dissertação]. Ribeirão Preto: Universidade de São Paulo; 2012.

37. Arsov S, Graaff R, Van Oeveren W, Stegmayr B, Sikole A, Rakhorst G, et al. Advanced glycation end-products and skin autofluorescence in end-stage renal disease: a review. Clin Chem Lab Med. 2014;52(1):11-20. 
38. Negre-Salvayre A, Salvayre R, Augé N, Pamplona R, Portero-Otín M. Hyperglycemia and glycation in diabetic complications. Antioxid Redox Signal. 2009;11(12):3071-109

39. Castro E. The role of advanced glycosylation end products in diabetic nephropathy. Arq Med. 2011;25(1):27-37.

40. Tan ALY, Forbes JM, Cooper ME. AGE, RAGE, and ROS in diabetic nephropathy. Semin Nephrol. 2007;27(2):130-43.

41. Stinghen AE, Massy ZA, Vlassara H, Striker GE, Boullier A. Uremic toxicity of advanced glycation end products in CKD. J Am Soc Nephrol. 2016;27(2)354-70.

42. Matsui T, Higashimoto Y, Nishino Y, Nakamura N, Fukami K, Yamagishi SI RAGE-aptamer blocks the development and progression of experimental diabetic nephropathy. Diabetes. 2017;66(6):1683-95.

43. Coughlan MT, Sharma K. Challenging the dogma of mitochondrial reactive oxygen species overproduction in diabetic kidney disease? Kidney Int. 2016;90(2):272-9

44. Zhu Q, Scherer PE. Immunologic and endocrine functions of adipose tissue: implications for kidney disease. Nat Rev Nephrol. 2018;14(2):105-20.

45. Chawla T, Sharma D, Singh A. Role of the renin angiotensin system in diabetic nephropathy. World J Diabetes. 2010;1(5):141-5.

46. Carmines PK. The renal vascular response to diabetes. Curr Opin Nephrol Hypertens. 2010;19(1):85-90.

47. Lim AKH. Diabetic nephropathy - complications and tratment. Int J Nephrol Renovasc Dis. 2014 Oct 15;7:361-81.

48. Bakris GL. Recognition, pathogenesis, and treatment of different stages of nephropathy in patients with type 2 diabetes mellitus. Mayo Clin Proc. 2011;86(5):444-56

49. Van Buren PN, Toto R. Hypertension in diabetic nephropathy: epidemiology, mechanisms, and management. Adv Chronic Kidney Dis. 2011;18(1):28-41.

50. Maric-Bilkan C. Obesity and diabetic kidney disease. Med Clin North Am. 2013:97(1):59-74

51. Márquez E, Riera M, Pascual J, Soler MJ. Renin-angiotensin system within the diabetic podocyte. Am J Physiol Renal Physiol.. 2015;308(1):F1-10.

52. Padda RS, Shi Y, LoCS., Zhang SL, Chan JS. Angiotensin-(1-7): a novel peptide to treathypertension and nephropathy in diabetes?.J Diabetes Metab. 2015;6(10).

53. Nguyen Dinh Cat A, Montezano AC, Burger D, Touyz RM. Angiotensin II, NADPH oxidase, and redox signaling in the vasculature. Antioxid Redox Signal. 2013;19(10):1110-20.

54. Parker MD, Myers EJ, Schelling JR. Na+-H+ exchanger-1 (NHE1) regulation in kidney proximal tubule. Cell Mol Life Sci. 2015;72(11):2061-74.

55. Vallés PG, Bocanegra V, Gil LA, Costantino VV. Physiological functions and regulation of the $\mathrm{Na}^{+} / \mathrm{H}^{+}$exchanger [NHE1] in renal tubule epithelial cells. Kidney Blood Press Res. 2015;40(5):452-66.

56. Peti-Peterdi J, Harris RC. Macula densa sensig and signaling mechanisms of renin release. J Am Soc Nephrol. 2010;21(7):1093-6.

57. Sedeek M, Nasrallah R, Touyz RM, Hébert RL. NADPH oxidases, reactive oxygen species, and the kidney: friend and foe. J Am Soc Nephrol. 2013;24(10):1512-8.

58. Lozano-Maneiro L, Puente-García A. Renin-angiotensin-aldosterone system blockade in diabetic nephropathy. Present evidences. J Clin Med. 2015;4(11):1908-37.

59. Miranda-Díaz AG, Pazarín-Villaseñor L, Yanowsky-Escatell FG, AndradeSierra J. Oxidative stress in diabetic nephropathy with early chronic kidney disease. J Diabetes Res. 2016;2016:7047238.

60. Lindblom R, Higgins G, Coughlan M, De Haan JB. Targeting mitochondriaand reactive oxygen species-driven pathogenesis in diabetic nephropathy. Rev Diabet Stud. 2015;12(1-2):134-56.
61. Sharaf El Din UAA, Salem MM, Abdulazim DO. Diabetic nephropathy: time to withhold development and progression - a review. J Adv Res. 2017;8(4):363-73.

62. Manda G, Checherita Al, Comanescu MV, Hinescu ME. Redox signaling in diabetic nephropathy: hypertrophy versus death choices in mesangial cells and podocytes. Mediators Inflamm. 2015;2015:604208.

63. Johar DR, Bernstein LH. Biomarkers of stress-mediated metabolic deregulation in diabetes mellitus. Diabetes Res Clin Pract. 2017 Apr; $126: 222-9$

64. Ruiz S, Pergola PE, Zager RA, Vaziri ND. Targeting the transcription factor Nrf2 to ameliorate oxidative stress and inflammation in chronic kidney disease. Kidney Int. 2013;83(6):1029-41.

65. Guo K, Lu J, Huang Y, Wu M, Zhang L, Yu H, et al. Protective role of PGC-1a in diabetic nephropathy is associated with the inhibition of ROS through mitochondrial dynamic remodeling. PLoS One. 2015;10(4):e0125176.

66. Tavafi M. Diabetic nephropathy and antioxidants. J Nephropathol. 2013;2(1):20-7.

67. Mahmoodnia, L, Aghadavod E, Beigrezaei S, Rafieian-Kopaei M. An update on diabetic kidney disease, oxidative stress and antioxidant agents. J Renal Inj Prev. 2017;6(2):153-7.

68. Bolignano D, Cernaro V, Gembillo G, Baggetta R, Buemi M, D'Arrigo G Antioxidant agents for delaying diabetic kidney disease progression: systematic review and meta-analysis. PLoS One. 2017;12(6):e0178699.

69. Barman, S, Pradeep, RP, Srinivasan K. Zinc supplementation alleviates the progression of diabetic nephropathy by inhibiting the overexpression of oxidative-stress-mediated molecular markers in streptozotocin-induced experimental rats. J Nutr Biochem. 2018;54:113-29.

70. Khatami PG, Soleimani A, Sharifi N, Aghadavod E, Asemi Z. The effects of high-dose vitamin $E$ supplementation on biomarkers of kidney injury, inflammation, and oxidative stress in patients with diabetic nephropathy: a randomized, double-blind, placebo-controlled trial. J Clin Lipidol. 2016;10(4):922-9.

71. Testa R, Bonfigli AR, Genovese S, Nigris VD, Ceriello, A. The possible role of flavonoids in the prevention of diabetic complications. Nutrients. 2016;8(5):E310.

72. Wada J, Makino H. Inflammation and the pathogenesis of diabetic nephropathy. Clin Sci. 2013;124(3):139-52.

73. Pichler R, Afkarian M, Dieter BP, Tuttle KR. Immunity and inflammation in diabetic kidney disease: translating mechanisms to biomarkers and treatment targets. Am J Physiol Renal Physiol. 2017;312(4):F716-31.

74. Duran-Salgado MB, Rubio-Guerra AF. Diabetic nephropathy and inflammation. World J Diabetes. 2014;5(3):393-8.

75. Sharma D, Bhattacharya P, Kalia K, Tiwari V. Diabetic nephropathy: new insights into established therapeutic paradigms and novel molecular targets. Diabetes Res Clin Pract. 2017 Jun;128:91-108.

76. Yap HL. MCP-1: a potential target for diabetic microvascular complications? Urol Nephrol Open Access J. 2017; 5(3):3-5

77. Anders $\mathrm{H}-\mathrm{J}$. Of inflammasomes and alarmins: IL-1 $\beta$ and IL- $1 \alpha$ in kidney disease. J Am Soc Nephrol. 2016:27(9):2564-75.

78. García-García PM, Getino-Melián MA, Domínguez-Pimentel V, NavarroGonzález JF. Inflammation in diabetic kidney disease. World J Diabetes. 2014;5(4):431-43.

79. Sakai N, Wada T. Revisiting inflammation in diabetic nephropathy: the role of the Nlrp3 inflammasome in glomerular resident cells. Kidney Int. 2015;87(1):12-4.

80. Sun L, Kanwar YS. Relevance of TNF- $\alpha$ in the context of other inflammatory cytokines in the progression of diabetic nephropathy. Kidney Int. 2015;88(4):662-5. 


\section{Review Article}

81. Chen $Y$, Qiao $Y, X u$ Y, Ling $W$, Pan $Y$, Huang $Y$, et al. Serum TNF- $\alpha$ concentrations in type 2 diabetes mellitus patients and diabetic nephropathy patients: a systematic review and meta-analysis. Immunol Lett. 2017 Jun;186:52-8.

82. Ratliff BB, Abdulmahdi W, Pawar R, Wolin MS. Oxidant mechanisms in renal injury and disease. Antioxid Redox Signal. 2016;25(3):119-46.

83. Sindhughosa DA, Pranamartha AGMK. The involvement of proinflammatory cytokines in diabetic nephropathy: focus on interleukin 1 (IL-1), interleukin 6 (IL-6), and tumor necrosis factor-alpha (TNF- $\alpha$ ) signaling mechanism. Bali Med J. 2017;6(1):44-51.
84. Feigerlová E, Battaglia-Hsu SF. IL-6 signaling in diabetic nephropathy: From pathophysiology to therapeutic perspectives. Cytokine Growth Factor Rev. 2017 Oct; 37:57-65.

85. Su H, Lei CT, Zhang C. Interleukin-6 signaling pathway and its role in kidney disease: an update. Front Immunol. 2017 Apr 21;8:405.

86. Elsherbiny NM, Al-GayyarMMH. The role of IL-18 in type 1 diabetic nephropathy: the problem and future treatment. Cytokine. 2016 May;81:15-22.

87. Fujita T, Ogihara N, KamuraY, Satomura A, FukeY, Shimizu C, etal. Interleukin-18 contributes more closely to the progression of diabetic nephropathy than other diabetic complications. Acta Diabetol. 2012;49(2):111-7. 